\title{
CAPACITATION OF MOUSE SPERMATOZOA IN VITRO: INVOLVEMENT OF EPIDIDYMAL SECRETIONS AND CUMULUS OOPHORUS
}

\author{
R. B. L. GWATKIN, O. F. ANDERSEN AND D. T. WILLIAMS
}

Merck Institute for Therapeutic Research, Rahway, New Jersey 07065, U.S.A.

(Received 3rd Fune 1974)

\begin{abstract}
Summary. Capacitation of mouse spermatozoa in vitro is brought about by epididymal secretions released into the medium at the time of sperm collection. Inhibition by glucaro $(1 \rightarrow 4)$ lactone indicates that an essential component of these secretions is $\beta$-glucuronidase. In the absence of the secretions, capacitation can be induced by components of the cumulus oophorus.
\end{abstract}

Current concepts of fertilization in mammals indicate that capacitation occurs in the oviduct rather than in the uterus (Edwards, 1972; Zamboni, 1972). Experiments with hamster gametes in vitro have shown that the active component is not the secretion of the oviduct, but the cumulus oophorus (Gwatkin, Andersen \& Hutchison, 1972; Gwatkin \& Carter, 1974). Glycosidases supplied by these cells alter the sperm surface (Gwatkin \& Andersen, 1973) so that it can bind to a trypsin-sensitive receptor in the zona pellucida (Hartmann \& Gwatkin, 1971; Gwatkin, Williams, Hartmann \& Kniazuk, 1973).

We now report experiments indicating that cumulus cells can also capacitate in vitro the spermatozoa of the laboratory mouse. To demonstrate this phenomenon, however, it is necessary to remove the epididymal secretions which are released into the medium at the time of sperm collection.

Spermatozoa were obtained by placing four pairs of epididymides in $0.5 \mathrm{ml}$ medium 199M2 (Gwatkin \& Andersen, 1973), contained within the cavity of a glass spot-test plate, and making several cuts in their caudae. The epididymides were then removed and the extruded secretions and spermatozoa were mixed and transferred to $2 \mathrm{ml}$ medium 199M2. The final concentration was approximately $2 \times 10^{7}$ motile spermatozoa $/ \mathrm{ml}$. Aliquots $(20 \mu \mathrm{l})$ were added to a series of 20- $\mu$ l drops of medium 199M2 or medium 199M2 containing approximately twenty eggs surrounded by cumulus, under a layer of mineral oil. Eggs in cumulus were obtained from 8- to 9-week-old mice approximately $17 \mathrm{hr}$ after ovulation had been induced by HCG. The cultures were incubated under an atmosphere of $5 \% \mathrm{CO}_{2}$ in air. At hourly intervals, the eggs in cumulus originally added were removed and twenty new cumulus-free eggs were introduced. Incubation was continued for another $90 \mathrm{~min}$. The eggs were then mounted on slides and examined for sperm penetration, as described previously (Gwatkin et al., 1972). 


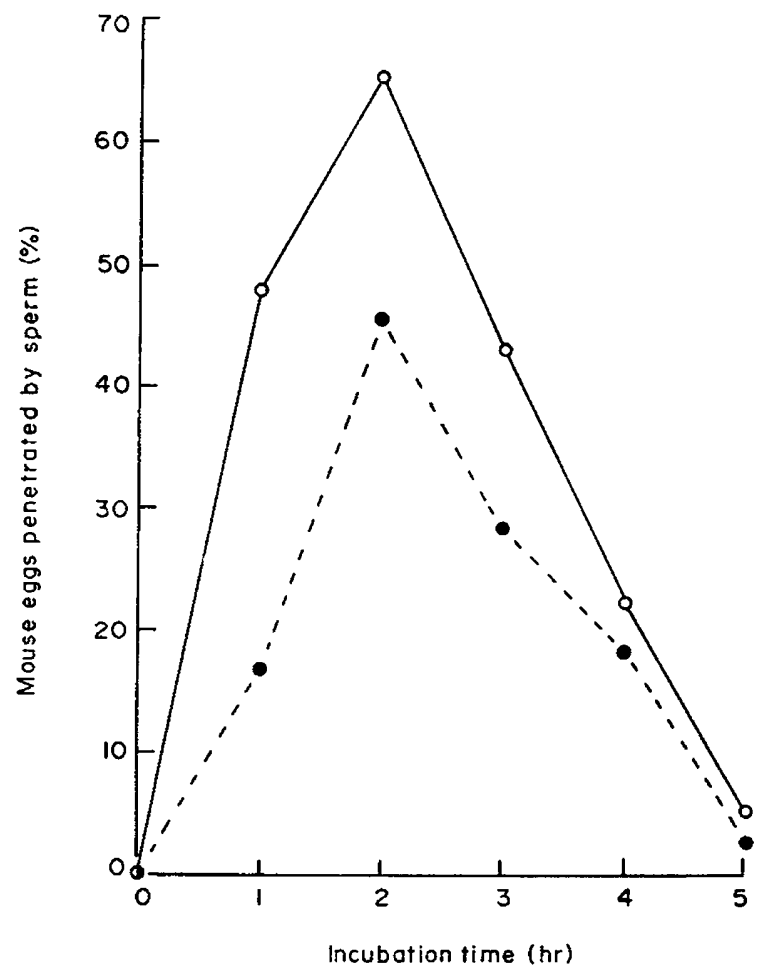

TEXT-FIG. 1. Proportion of mouse eggs penetrated by spermatozoa which were preincubated for various periods of time with medium 199M2 (O) and with medium 199M2 supplemented with cumulus oophorus (O). Each point represents the mean of sixty eggs.

Text-figure 1 shows the effect of preincubating the sperm suspension in medium 199M2 alone (lower curve) or with cumulus cells (upper curve) on the ability of the spermatozoa to enter eggs. Without preincubation, no eggs were penetrated. After $1 \mathrm{hr}$ in medium 199M2, spermatozoa entered approximately $15 \%$ of the eggs. After $2 \mathrm{hr}$, this proportion increased to $45 \%$. Incubation for a longer period reduced the proportion of eggs which were penetrated. Response to preincubation with cumulus cells followed a similar time-response curve, but a greater proportion of the eggs were penetrated, the maximum being $65 \%$.

To determine whether capacitation of the spermatozoa was being produced by the epididymal secretions released into the medium during sperm collection, the secretions were removed by centrifugation at $150 \mathrm{~g}$ for $4 \mathrm{~min}$ and the spermatozoa were resuspended in medium 199M2. When $20-\mu \mathrm{l}$ aliquots were incubated for $2 \mathrm{hr}$ with an equal volume of medium 199M2, the spermatozoa failed to penetrate eggs (Table 1) although they remained actively motile. When spermatozoa were incubated with cumulus cells, or resuspended in the original supernatant containing the epididymal secretions, penetration occurred. Capacitation was blocked when the specific $\beta$-glucuronidase inhibitor, glucaro$(1 \rightarrow 4)$ lactone (Levvy, 1952), was added at the beginning of preincubation 
Table 1. Capacitation of mouse spermatozoa induced by cumulus oophorus and by epididymal secretions

\begin{tabular}{|c|c|}
\hline Supplements & $\begin{array}{l}\% \text { Eggs penetrated } \\
\text { by spermatozoa } \\
\text { Exp. } 1 \quad \text { Exp. } 2\end{array}$ \\
\hline $\begin{array}{l}\text { None } \\
\text { Gumulus oophorus } \\
\text { Epididymal secretions } \\
\text { Epididymal secretions }+ \text { cumulus } \\
\text { Epididymal secretions }+ \text { GL, } \dagger \text { added before } \\
\text { capacitation } \\
\text { Epididymal secretions + GL, added after capacitation }\end{array}$ & $\begin{array}{r}0 \\
40 \\
40 \\
50 \\
0 \\
60\end{array}$ \\
\hline
\end{tabular}

with the secretions. When the inhibitor was added at the end of preincubation, it had no effect.

These experiments demonstrate that capacitation of mouse spermatozoa requires approximately $2 \mathrm{hr}$ to reach a maximum. They also show that capacitation is induced by the cumulus oophorus, but that this may be masked by the capacitation caused by the epididymal secretions, one essential component of which appears to be $\beta$-glucuronidase. The 2-hr period required for capacitation of mouse spermatozoa agrees with the results of Toyoda, Yokoyama \& Hosi (1971), who capacitated mouse spermatozoa by incubating them in a modified Krebs-Ringer solution. These authors did not remove the epididymal secretions, however, and this led them to conclude that they had induced capacitation in a chemically defined medium when, in fact, their conditions were far from defined by the medium used. Epididymal secretions are known to contain high concentrations of glycosidases (Conchie \& Mann, 1957) which have been implicated in the capacitation of hamster spermatozoa (Gwatkin \& Andersen, 1973). Even in the presence of these secretions, preincubation with the cumulus oophorus increased the proportion of eggs which became penetrated. These results support the findings of Pavlok \& McLaren (1972), who observed a beneficial effect of cumulus cells on the fertilization of mouse ova in vitro by a suspension of epididymal spermatozoa from which the epididymal secretions were not removed.

\section{REFERENGES}

ConchIE, J. \& MANN, T. (1957) Glycosidases in mammalian sperm and seminal plasma. Nature, Lond. $179,1190$.

EDWARDs, R. G. (1972) Current concepts on fertilization in mammals. Res. Reprod. 4, 3.

Gwatkin, R. B. L. \& ANDERSEN, O. F. (1973) Effect of glycosidase inhibitors on the capacitation of hamster spermatozoa by cumulus cells in vitro. 7. Reprod. Fert. 35, 565.

Gwatkin, R. B. L., Andersen, O. F. \& Hurchison, C. F. (1972) Capacitation of hamster spermatozoa in vitro: the rôle of cumulus components. F. Reprod. Fert. 30, 389.

Gwatkin, R. B. L. \& Carter, H. E. (1974) Cumulus oophorus. In Scanning Electron Microscopic Atlas of Mammalian Reproduction, Ed. E. S. E. Hafez. Igaku Shion, Tokyo.

Gwatkin, R. B. L., Williams, D. T., Hartmann, J. F. \& Kniazuk, M. (1973) The zona reaction of hamster and mouse eggs : production by a trypsin-like protease from cortical granules. F. Reprod. Fert. 32, 259. 
Hartmann, J. F. \& Gwatkin, R. B. L. (1971) Alteration of sites on the mammalian sperm surface following capacitation. Nature, Lond. 234, 479.

Levvy, G. A. (1952) The preparation and properties of $\beta$-glucuronidase. 4 . Inhibition by sugar acids and their lactones. Biochem. F. 52, 464.

Pavlok, A. \& McLaren, A. (1972) The rôle of cumulus cells and the zona pellucida in fertilization of mouse eggs in vitro. 7. Reprod. Fert. 29, 91.

Toyoda, Y., Yokoyama, M. \& Hosi, T. (1971) Studies on the fertilization of mouse eggs in vitro. Jap. 7. Reprod. 16, 147 and 152.

Zamboni, L. (1972) Fertilization in the mouse. In Biology of Mammalian Fertilization and Implantation, Chap. 8, pp. 213-262. Eds. K. S. Moghissi and E. S. E. Hafez. Charles G. Thomas, Springfield. 